Document downloaded from:

http://hdl.handle.net/10251/158499

This paper must be cited as:

Sanchez-Rojas, L.; Gómez-Pinedo, U.; Benito-Martin, MS.; León-Espinosa, G.; RascónRamirez, F.; Lendinez, C.; Martínez-Ramos, C.... (2019). Biohybrids of scaffolding hyaluronic acid biomaterials plus adipose stem

cells home local neural stem and endothelial cells: Implications for reconstruction of brain lesions after stroke. Journal of Biomedical Materials Research Part B Applied Biomaterials. 107(5):1598-1606. https://doi.org/10.1002/jbm.b.34252

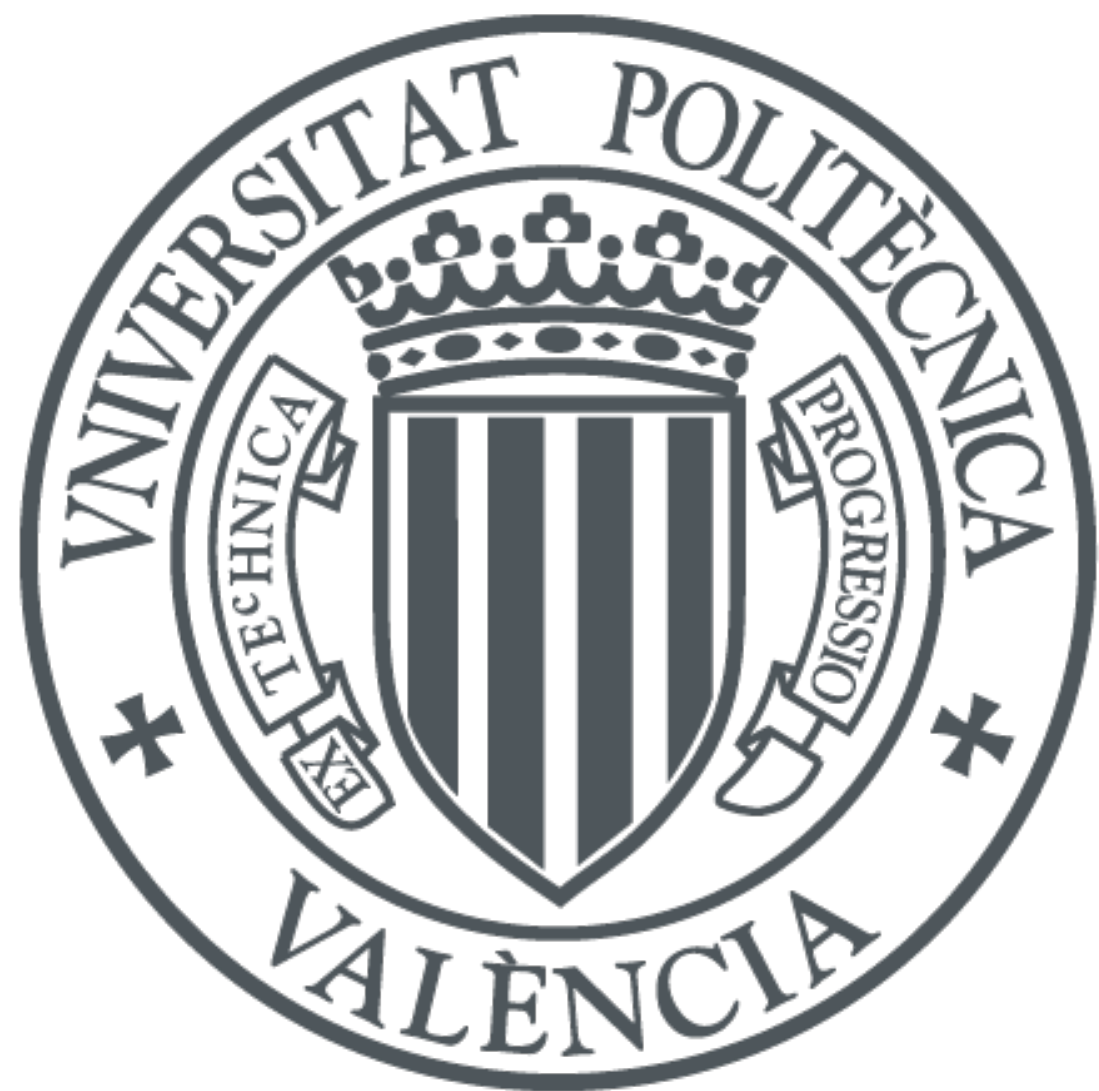

The final publication is available at

https://doi.org/10.1002/jbm.b.34252

Copyright John Wiley \& Sons

Additional Information 


\title{
Biohybrids of scaffolding hyaluronic acid biomaterials plus adipose stem cells home local neural stem and endothelial cells: Implications for reconstruction of brain lesions after stroke
}

\author{
Leyre Sanchez-Rojas, ${ }^{1 \dagger}$ Ulises Gómez-Pinedo, ${ }^{1}$ María Soledad Benito-Martin, ${ }^{1}$ \\ Gonzalo León-Espinosa, ${ }^{1,2}$ Fernando Rascón-Ramirez, ${ }^{3}$ Cristina Lendinez, ${ }^{1}$ Cristina Martínez-Ramos, ${ }^{4}$ \\ Jorge Matías-Guiu, ${ }^{6}$ Manuel Monleón Pradas, ${ }^{4,5}$ Juan A. Barcia $^{3}$ \\ ${ }^{1}$ Laboratorio de Medicina Regenerativa, Instituto de Neurociencias, Instituto de Investigación Sanitaria San Carlos (IdISSC), \\ Hospital Clínico San Carlos, Madrid, Spain \\ ${ }^{2}$ Instituto Cajal, CSIC; Laboratorio Cajal de Circuitos Corticales (CTB), Universidad Politécnica de Madrid; Facultad de Farmacia, \\ Universidad San Pablo CEU, Madrid, Spain \\ ${ }^{3}$ Servicio de Neurocirugía, Instituto de Investigación Sanitaria San Carlos (IdISSC), Hospital Clínico San Carlos, Universidad \\ Complutense de Madrid, Madrid, Spain \\ ${ }^{4}$ Center for Biomaterials and Tissue Engineering, Universitat Politécnica de Valencia, C. de Vera s/n, Valencia, Spain \\ ${ }^{5}$ Networking Research Center on Bioengineering, Biomaterials and Nanomedicine, Valencia, Spain \\ ${ }^{6}$ Servicio de Neurología. Instituto de Investigación Sanitaria San Carlos (IdISSC), Hospital Clínico San Carlos, Universidad \\ Complutense de Madrid, Madrid, Spain
}

\begin{abstract}
Endogenous neurogenesis in stroke is insufficient to replace the lost brain tissue, largely due to the lack of a proper biological structure to let new cells dwell in the damaged area. We hypothesized that scaffolds made of hyaluronic acid $(\mathrm{HA})$ biomaterials (BM) could provide a suitable environment to home not only new neurons, but also vessels, glia and neurofila- ments. Further, the addition of exogenous cells, such as adipose stem cells (ASC) could increase this effect. Athymic mice were randomly assigned to a one of four group: stroke alone, stroke and implantation of BM, stroke and implantation of BM with ASC, and sham operated animals. Stroke model consisted of middle cerebral artery thrombosis with $\mathrm{FeCl}_{3}$. After 30 days, ani- mals underwent magnetic resonance imaging (MRI) and were
\end{abstract}

\section{INTRODUCTION}

In spite of the extensive pharmacological and neurorehabilitation efforts made to recover the neurological deficits, stroke is still the main cause of disability in the occidental world. Ischemic stroke produces an area of necrosis (core zone) surrounded by a partially damaged zone (area of sacrificed. Proliferation and neurogenesis increased at the subventricular zone ipsilateral to the ventricle and neuroblasts, glial, and endothelial cells forming capillaries were seen inside the BM. Those effects increased when ASC were added, while there was less inflammatory reaction. Three-dimensional scaffolds made of $\mathrm{HA}$ are able to home newly formed neurons, glia, and endothelial cells permitting the growth neurofilaments inside them. The addition of ASC increase these effects and decrease the inflammatory reaction to the implant. (c) 2018 Wiley Periodicals, Inc. J Biomed Mater Res B Part B: 00B: 000-000, 2018.

Key Words: biomaterials, hyaluronic acid, cell therapy, adipose stem cells, stroke

penumbra). ${ }^{1}$ Most of the therapeutic efforts up to now have been directed to reduce the extent and to improve the functional recovery of the penumbra zone. ${ }^{2}$ However, there is not a reliable way to repair the lost tissue. ${ }^{3}$

After an experimental stroke, there is an increase of the neurogenesis at the subventricular zone (SVZ), a main adult

Additional Supporting Information may be found in the online version of this article.

${ }^{\dagger}$ Both authors contributed equally to this work.

Correspondence to: S. de Neurocirugía; e-mail: jabarcia@ucm.es; gina.research.group.hcsc@gmail.com

Contract grant sponsor: CIBER BBN

Contract grant sponsor: ERANET NEURON CALL; contract grant number: PRI-PIMNEU-2011-1372

Contract grant sponsor: Spanish Science \& Innovation Ministery; contract grant number: MAT 2011 - 28791-C03-01, MAT 2011- 28791-C03-02 an

Contract grant sponsor: TERCEL; contract grant number: RD12/0019/0010

Contract grant sponsor: Spanish Ministry of Economy and Competitiveness through grants MAT2015-66666-C3, and DPI2015-72863-EXP 
neurogenic niche, especially at the ipsilateral hemisphere, and new neurons and supporting cells migrate massively to the area of infarction. ${ }^{4}$ However, most of these cells disap- pear from the lesion by the 5 th week. ${ }^{5}$ We hypothesize that the main reason for this is the lack of a proper substrate where the cells can survive, reconnect, and recover their function due to the generation of an adverse environment after the stroke $\mathrm{e}^{6,7}$ and/or to the absence of a material scaf- fold upon which new neurons and supporting structures such as glia and vessels can grow and organize.

The use of three-dimensional (3D) biomaterials (BM) could provide a proper scaffold for these newly formed cells, permitting the organization of neural tissue with neu- rons, glial cells and vessels, guiding the neurite prolonga- tions and providing a more appropriate environment for neural regeneration. ${ }^{8-12}$ Among the multiple available biocompatible materials, we chose hyaluronic acid (HA) because this is an already used BM in other clinical applications and it is simple to make and manipulate. ${ }^{13,14}$

Furthermore, mesenchymal stem cells have been shown to home endogenous stem cells close to the infarcted area, as well as to increase neovascularization at the same site and proliferation at the SVZ, and also to diminish the inflammatory reaction at the lesion site. ${ }^{15-18}$ We hypothesized that the addition of mesenchymal stem cells to the BM would increase their capacity to home endogenous stem cells, and possibly to facilitate their entry into the BM by inhibiting the scar reaction around the scaffold. ${ }^{19,20}$ Among the mesenchymal cells available, we have chosen adipose stem cells (ASCs) because of practical reasons: they are easily handled, they are widely available from lipoaspirate donation for allo- genic use and our group has already shown their potential benefits for clinical application in stroke. ${ }^{21-23}$

The objectives of this study were to determine if 3D scaffolds of hyaluronic acid (HA) implanted at the penumbra zone of a vascular stroke lesion in rats were able to home local neural and endothelial cells and neurites, and also to compare these homing capacities between BM co-grafted with adult human ASC and BM without them, as well as to study the host's reaction to the implant in both cases, both in terms of glial scar formation and neurogenetic production.
Also, if this represents a viable and safe method in order to transfer this to the clinical practice.

\section{MATERIALS AND METHODS}

Preparation of HA porous scaffolds

HA porous scaffolds were made as described Rodríguez- Pérez et al. ${ }^{24}$ Briefly, HA sodium salt from Streptococcus equii (1.51.8 MDa; Sigma-Aldrich) was dissolved overnight to a $5 \%$ $(\mathrm{w} / \mathrm{v})$ in $0.2 \mathrm{M}$ sodium hydroxide $(\mathrm{NaOH}, \mathrm{Scharlab})$. Then, divinyl sulfone (DVS, Sigma-Aldrich) was added as a crosslinker in a 9:10 DVS:HA monomeric units molar ratio. Once homogenized for $10 \mathrm{~s}$ more, the solution was vaccuuminjected into molds made from sintered beads of poly (ethyl methacrylate; PEMA, Elvacite ${ }^{\circledR} 2043$, Lucite International, Inc.). These beads had a diameter of between 180 and 250 $\mu \mathrm{m}$. The crosslinking reaction of HA with DVS was left to complete for an hour and a half.

After that, PEMA beads template was removed by leaching reflux in a Soxhlet extraction apparatus using boiling ethanol as solvent for $48 \mathrm{~h}$. Afterwards, HA scaffolds were immersed in distilled water for $3 \mathrm{~h}$, frozen at $-20^{\circ} \mathrm{C}$ for another $2 \mathrm{~h}$ and then lyophilized. All scaffolds were cut into cylinders with $0.8 \mathrm{~mm}$ diameter and $8 \mathrm{~mm}$ of length. Other tests were carried out to warrant the absence of pyrogens or endotoxins, to guarantee biomaterial's innocuity.

\section{Analysis of 3D structure of biomaterials}

The HA scaffolds, previously sterilized by chemical means, were analyzed by scanning electron microscopy to analyze the 3D configuration of the scaffold, ensuring that pores are between 300 and 150 um in diameter were present, so that ASC can easily enter the BM. For this purpose, they were processed in a critical dot dryer, followed by gold-palladium shading to provide electroconductivity to the sample and analyzed in a scanning electron microscope JEOL JSM 5410 with a voltage of $10 \mathrm{KV}$ at different magnitudes (Figure 1).

Adipose stem cells

Adipose tissue samples were obtained from donors during routine abdominoplasty following informed patient consent and according to the guidelines set by the corresponding
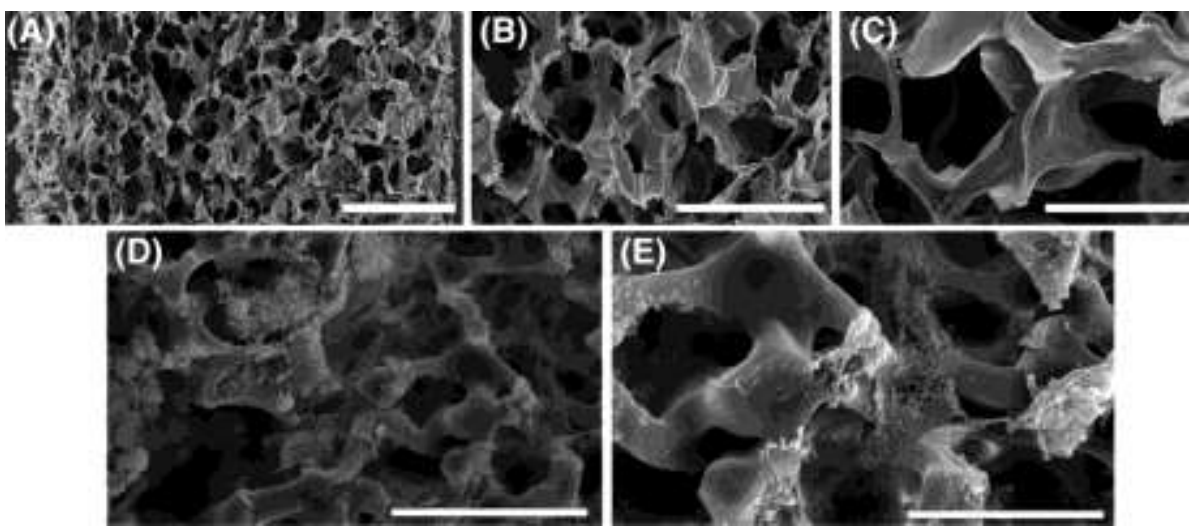

FIGURE 1. Scanning electronic micrographs showing porous scaffolds made of hyaluronic acid at different magnifications (A-D). A-C: shows images of the biomaterial and the characteristics of the scaffolding and D-E: images of ASC cells colonizing the scaffold. Scale Bar A: $500 \mu \mathrm{m}, \mathrm{B}$ : $300 \mu \mathrm{m}, \mathrm{C}$ : $150 \mu \mathrm{m}, \mathrm{D}: 80 \mu \mathrm{m}$, and $\mathrm{E}: 30 \mu \mathrm{m}$. 
Ethics Committee on Biomedical Research. The adipose tissue was transported in sterile bottles and immediately processed to obtain the ASC and process under GMP conditions (Histocell, S.L., Bilbao, Spain). Phenotype characteristics, clonic capacity and stem cell differentiation biomarkers as described by Gomez-Pinedo et al. ${ }^{23}$

The ASC were maintained until phase 7 in culture on the material to perform studies of telomerase and C-myc expression, to guarantee the stability of the cultured cells on the biomaterial. Before use, we proceeded to carry out the immunophenotype of the ASC cells to be considered mesenchymal stem cells and useful for our purpose.

Scaffold preloading

ASC were used in the fourth cell phase. Cells were resuspended in culture medium at a concentration of $5 \times 10^{4} / 4 \mu \mathrm{L}$. This concentration was inoculated inside the HA biomaterial (dimensions for the preclinical study of $1 \times 1 \mathrm{~mm}$ ) with the help of a Hamilton ${ }^{\circledR}$ microsyringe. The biomaterials inoculated with ASC were maintained in 24-well plates with the culture medium composed of DMEM-Glutamax + Antibiotic / $10 \%$ FBS and incubated at $37^{\circ} \mathrm{C} / 5 \% \mathrm{CO}_{2}$ for $72 \mathrm{~h}$, for subsequent implant in the model of athymic nude mice [Figure 1(D-E)].

$\mathrm{FeCl}_{3}$ thrombosis model

Nude-Foxn1Nu/nu (dEnvigo -Harlan Laboratories) adult male mice were used for the experiments. At 7 weeks of age were housed in a temperature-controlled room with access to food and water ad libitum. They were kept in individual cages and under standard conditions in the animal facilities of the Hospital Clínico San Carlos. All procedures were carried out under animal welfare regulations in accordance with EC Council Directive November 24, 1986 and approved by the local ethics committee.

Mice were anesthetized with $80-100 \mathrm{mg} / \mathrm{kg}$ ketamine and $10 \mathrm{mg} / \mathrm{kg}$ xylazine. A small craniotomy was performed to access the middle cerebral artery. For the formation of the ischemia model, a $\mathrm{FeCl}_{3}$ solution (20\%) was applied to the surface of the artery for $1 \mathrm{~min}$. In the control group (sham) $0.9 \%$ of saline solution was used. ${ }^{15,16}$

Experimental and control groups

Four groups were defined: Stroke (mice subjected to the stroke model), Stroke+BM (mice subjected to the stroke model to whom HA biomaterials alone were implanted at the core zone), Stroke+BM+ASC (mice subjected to the stroke model to whom HA biomaterials co-grafted with ASC were implanted at the core zone) and sham (animals under- going the operation for the stroke model except the applica- tion of the thrombotic $\mathrm{FeCl}_{3}$ solution). Six animals were assigned randomly to each group.

Seven days after the ischemic procedure, animals belonging to groups Stroke+BM and Stroke+BM+ASC were again anesthetized and the wound reopened. A burr hole was performed at the cranial vault just medial to the temporal crest
(A)
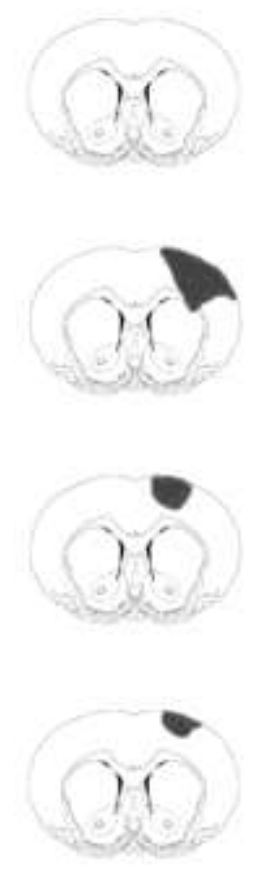

Ischemic

Zone
(B)
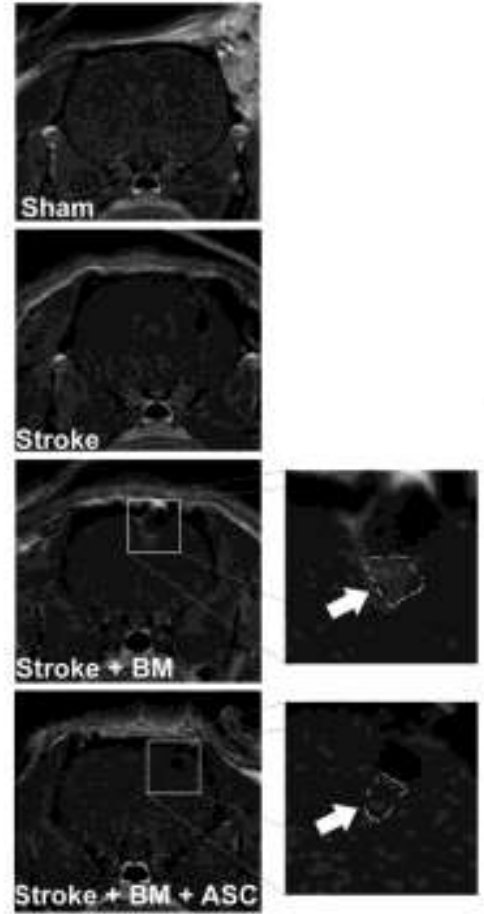

(C)

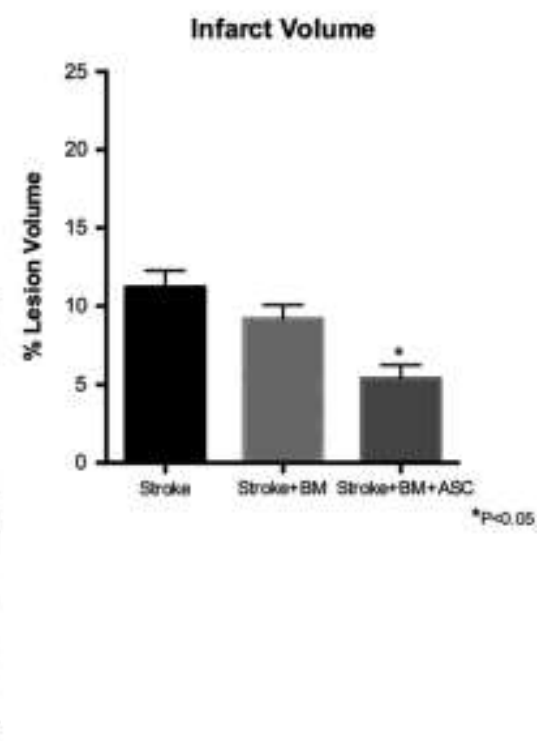

FIGURE 2. Magnetic resonance imaging demonstrating the infarcted area in the control group (only stroke) and the implanted groups. In the latter, the biomaterial is fully integrated, and it is associated with less cavitation. 

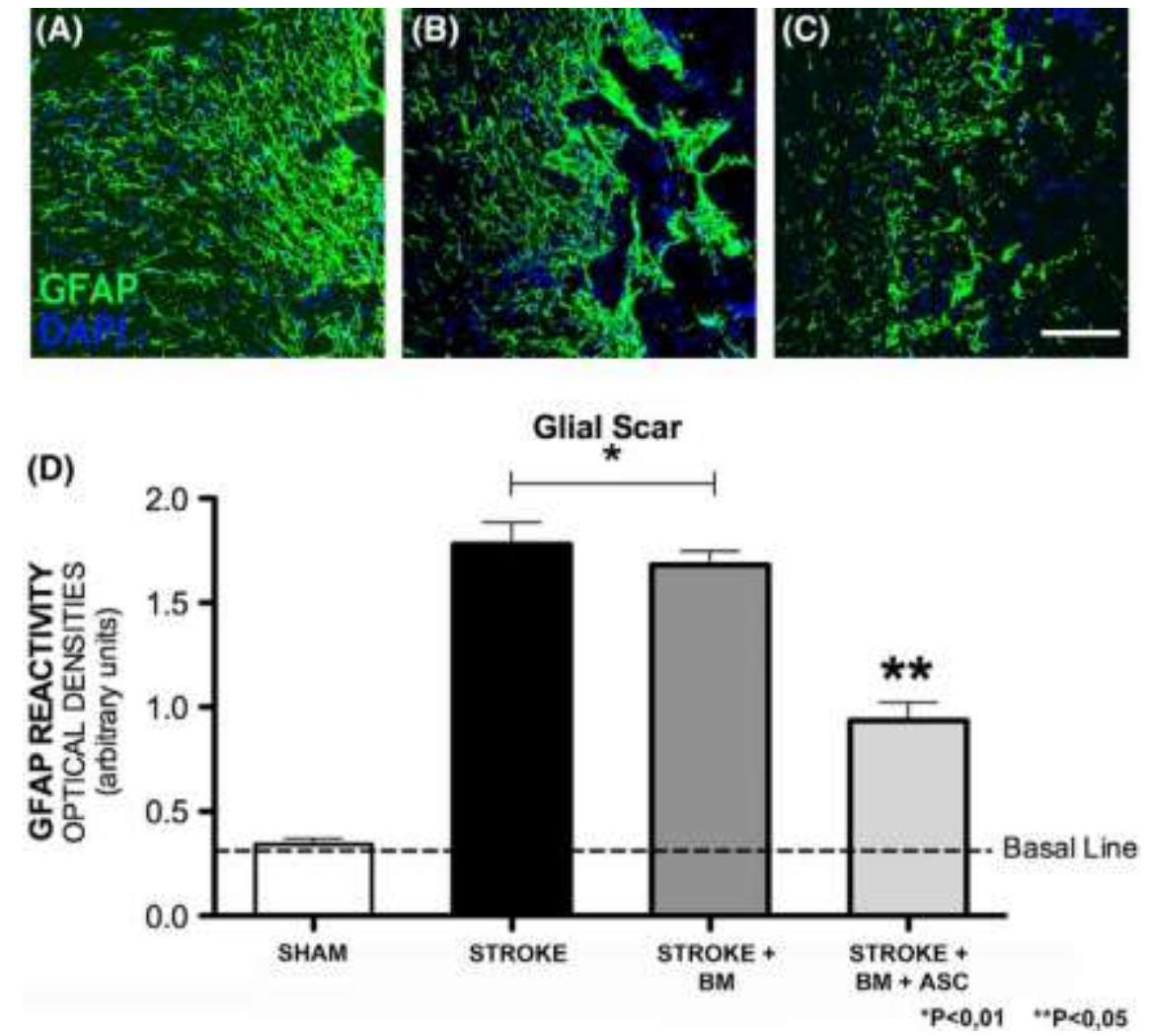

FIGURE 3. Analysis of the glial scar. Representative immunohistochemical image showing glial fibrillary acidic protein (GFAP), (A) stroke; (B) stroke +BM; (C) stroke+BM+ASC; (D) The graph shows that in the group of animals with stroke, in which ASC were administered in biomaterials, they showed less expression of the GFAP, in the other two groups (stroke and stroke+BM) the expression of GFAP was significantly higher $\left({ }^{* *} p<0.05\right.$ and ${ }^{*} p<$ 0.01) Scale Bar: $100 \mu \mathrm{m}$

at the same coronal plane at which the occluded MCA branch was located. A cannula was inserted to implant the biomaterials (with or without ASC) at a depth of $13 \mathrm{~mm}$ from the dural plane. (Supporting Information Figure 2).

Magnetic resonance imaging

The day of the sacrifice, the mice were anesthetized with isoflurane $1.5-2 \%$ to obtain a brain MRI. All the MRI experiments were performed on a BIOSPEC BMT 47/40 (Bruker, Ettlingen, Germany) spectrometer operating a $4.7 \mathrm{~T}$, equipped with a $11.2 \mathrm{~cm}$ actively shielded gradient system, capable of 200 $\mathrm{mT} / \mathrm{m}$ gradient strength and $80 \mu$ s of rise time. During the MRI procedure, the animals were kept at $37^{\circ} \mathrm{C}$ and a MR com- patible respiration sensor was used to control the animals. The MRI experiments consisted of three-dimensional T2WI, a series of DWI to calculate the ADC maps and a series of PWI to calculate CBF maps. A 7-cm birdcage radiofrequency coil was used for transmission and reception. Image analysis was performed using ParaVision 3.0.1 (Bruker, Ettlingen, Germany). This calcu- lation was carried out using MATLAB 7.3 (MathWorks, Inc., Natick, MA).

BrdU administration. The BrdU is an analog of the thymi- dine that the cell incorporates in the cellular cycle when entering into cellular division. Two hours before the sacrifice of the animals an intraperitoneal pulse of $\operatorname{BrdU}(60 \mathrm{mg} / \mathrm{kg}$,
Sigma-Aldrich) dissolved in physiological saline was administrated to evaluate the proliferative activity of the endoge- nous stem cells in the SVZ, as well as implanted ASC cells. ${ }^{23}$

At 37 days after stroke surgery, mice in each group were anesthetized with a dose of pentobarbital $(60 \mathrm{mg} / \mathrm{kg})$ and fentanyl $(0.3 \mathrm{mg} / \mathrm{kg})$ for subsequent intracardiac infusion with $0.9 \%$ solution Saline followed by $4 \%$ buffered paraformaldehyde (0.1 M phosphate buffer). After perfusion, the brain was removed and washed with $0.1 \mathrm{M} \mathrm{PB}$ and cryoprotected by immersion in $30 \%$ sucrose. The cuts were performed in a cryostat (model Micron 1800) at 50 microns thick containing the infarct area and the biomaterial implant area.

Histochemistry and immunofluorescence analysis

The sections were washed with PBS, permeabilized with $0.1 \%$ Triton X-100 and blocked with 10\% normal goat serum. The following primary antibodies were then applied overnight at $4^{\circ} \mathrm{C}$ : anti-HuNu (Millipore, human cells); GFAP (Dako Cytomation, astrocytes); Anti-CD31 (Abcam, newly formed endothelium); Anti-NueN (Millipore, neurons); Anti- DCX (Santacruz, neuroblasts); Anti-BrdU (Millipore, thymi- dine analogue); Anti-NF 160 and anti-NF 200 (Millipore, neurofilaments). Subsequently the samples were washed in PBS three times for subsequent incubation in Alexa 488, 555, or 647 (1:500, Invitrogen) conjugated secondary 
TABLE I. Counting of Immature (NF $160 \mathrm{kD}$ ) and Mature (NF 200 kD) Neurofilaments Found in the Ischemic Zone in Stroke Controls, Stroke Animals After Placement of Biomateriales, and After Placement of Biomaterials with ASC (Units: Neurofilaments Per $\mathrm{mm}^{3}$ )

$$
\text { NF in the Ischemic Zone NF Into Biomaterial }
$$

Group

$$
\overline{\text { NF } 160 \text { kD NF } 200 \text { kD }} \overline{\text { NF } 160 \text { kD NF } 200 \text { kD }}
$$

\begin{tabular}{lccccc}
\hline Stroke & $9.3 \mathbf{T} 6.7$ & 2.1 T 1.9 & - & - \\
Stroke+ASCs & - & - & 36.2 T 17.9 & 12.6 T9.4 \\
Stroke+BM+ASC & - & - & 89.7 T 13.2 & 20.4 T3.7 \\
\hline
\end{tabular}

Volume analyzed $0.69 \mathrm{~mm}^{3}$.

antibodies, DAPI-contracted and mounted with the Fluorsave reagent (Calbiochem). Immunofluorescence images were obtained with the Olympus AF2000 confocal microscope.

The quantitative study both at the SVZ and at the areas around the biomaterial consisted in the analysis of 10 different fields for each of the antibodies studied (BrdU, DCX, and GFAP) and the result was the average of 10 determinations. Within the BM, a volumetric analysis was performed using confocal microscopy of 12 optical segments $800 \mathrm{~nm}$ thick.

The NF were counted in four optical planes by confocal microscopy in $\mathrm{z}$ projection. In cases where the unit of measurement was the observed mark quantity per field (Optical Density, D0), the software program Image J, v1.46r of the National Institutes of Health was used for its calculation.

To estimate the DCX/DAPI index, DAPI-positive and DCXpositive cells were quantified in an area of 300 microns from the ischemic border region at the per-infarct zone. This estimation consists in the number of DCX+ cells divided per the total amount of cells (counted by their nuclei, which is stained with DAPI). Quantification was performed under blind condition.

Statistical analysis

Results are reported as the mearSD. Differences between means were determined by Student's $t$ test, with $p<0.05$ considered significant. One-way analysis of variance followed by the Bonferroni post hoc multiple comparisons test was used to draw comparisons between three groups. We used the program SPSS Statistics 20.0. For the graphical representation of results, the Prism v 5.0 Graph Pad program was used. All data are expressed as mean standart error. The graphs of the results were performed using the same pro-

gram. The criterion for statistical significance was $p<0.05$.

\section{RESULTS}

After $72 \mathrm{~h}$ of incubation, cells were easily inserted into the scaffolds, and they were adhered to the walls of the same in a homogeneous way (Figure 1). Karyotype and phenotype did not show any alteration.

The application of $\mathrm{FeCl}_{3}$ induced a limited and constant brain infarction located at the left parietotemporal cortex (Supporting Information Figure 1). Neurological deficits appearared $4 \mathrm{~h}$ after the surgery, as forelimb flexion, resistance to lateral push and circling behavior; but all animals returned to a normal neurological examination $12 \mathrm{~h}$ later.

Animals did not show any further neurological alteration after the implant of the biomaterials, without inducing or inciting fever or implant rejection, suggesting the absence of pyrogenic elements. Magnetic resonance imaging showed that the implanted biomaterials were fully integrated into the host tissue and reduced the cavitation provoked by stroke in control animals. The reduction was more evident when ASC were added to the biomaterials (Figure 2).

After stroke, there was an astrocytic reaction around the infarcted area. The astrocytic reaction to the biomaterial was not intense (similar to the one produced with stroke alone), but it was much less to the biomaterials precharged with ASC, as we show in Figure 3 (Sham: 0.341 0.028 Stroke: 1.780 0.106; Ttroke+BM: 1.681 0.066; Strqke+BM+ASC: 0.935 (т.0868).

Neurofilaments were scarcely seen at the infarcted area in control animals, but they were found within the biomate- rials. After 30 days of scaffold implantation (with or without ASC) more neurofilaments, both immature (160 kD) and mature (200 kD), were encountered inside the biomaterial
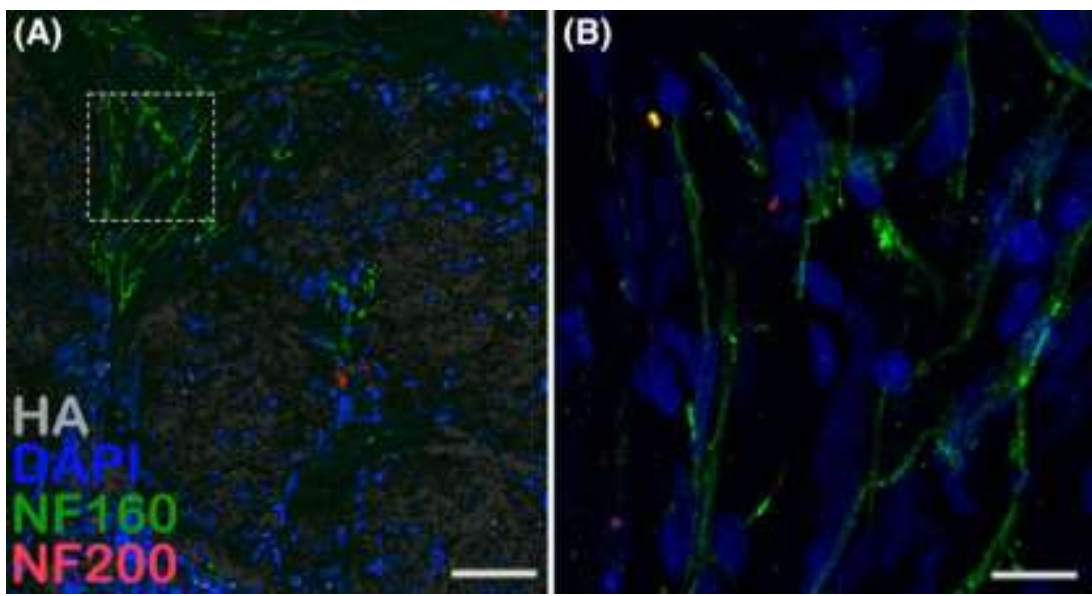

FIGURE 4. Immunohistochemical image showing the neurofilaments found inside the biomaterial+ASC 30 days after implantation. (HA: hyaluronic acid, DAPI: nucleus, NF160: 160 kD neurofilaments, NF200: 200 kD neurofilaments. Scale Bar: $100 \mu m$ B: Detail from image A. Scale Bar: 10 um. 


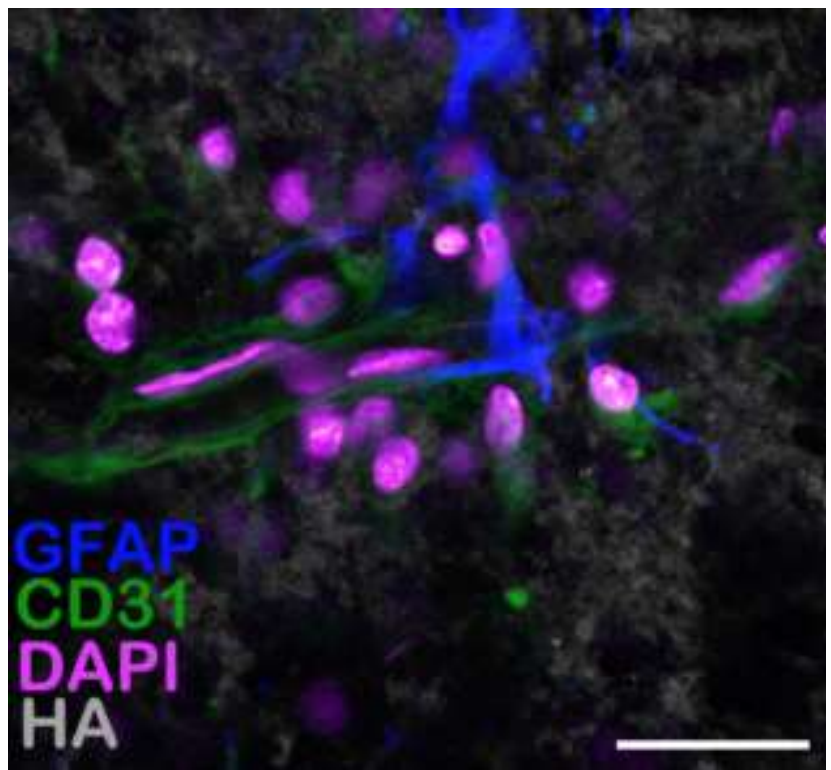

FIGURE 5. Immunohystochemical image showing implanted biomate- rials plus ASC, showing CD31 positive cells inside, forming vessel-like structures. Scale Bar: $50 \mu \mathrm{m}$.

than in the periphery of the lesion or in the controls (Table I).

More neurofilaments were seen in the biomaterial plus ASC than in the one without them. Most of the neurofi- laments were immature (160 kD) (Stroke: $9.3 \quad 6.7 ; \quad \mathbf{T}$ Stroke+BM: 36.2 T 17.9; Stroke+BM+ASC: 89.7 T 13.2; Table I and Figure 3), but mature neurofilaments (200 kD) were also seen (Stroke: 2.1 T 1.9; Stroke+BM: 12.6 T 9.4;
Stroke+BM+ASC: 20.4 p.7, data expressed in NF into biomaterial; Table I and Figure 4).

CD31 positive cells were seen inside the implants (Figure 5 ), but not in the infarcted area in control animals. Some of them were organized in tubule-like structures, resembling vessels. Also, more CD31 positive cells were seen inside the biomaterials pre-charged with ASC.

There was a proliferative reaction at the SVZ after the stroke, in the number of BrdU (Sham: $122 \mathbf{T}$ 8; Stroke: $174 \mathbf{T} 16$; Stroke+BM: 241 T 11; Stroke+BM+ASC: 305 T26) DCX (Sham: 0.51 T 0.07; Stroke: 0.94 T 0.08; Stroke+BM: 1.52T 0.09; Stroke+BM+ASC: $1.83 \mathbf{p} .12$ ) positive cells. The implantation of biomaterials increased this reaction. The preloaded cells (ASC) increased even further this effect (Figure 6).

Newly formed neurons showing DCX were not seen inside the infarcted areas in control animals, although some of them were seen in the vicinity of the core zone. More cells were seen in the vicinity of the scaffold alone and even more around the biomaterials plus ASC. Inside the biomaterials we found some newly formed neuroblasts, and this number increased when ASC were co-grafted (Stroke: 0.032 0.00ฐ2; Stroke+BM: 0.061 0.0096 Stroke+BM+ASC: 0.096 0.0169; Frgure 7).

Neither $\mathrm{HuNu}$ positive cells, not teratomas or any other neoplasic formation were found inside the biomaterials or in the surrounding brain tissue after 30 days of implantation of human ASC.

\section{DISCUSSION}

Here, we show that the implant of biomaterials made of HA at the core of a brain stroke lesion permits the migration of endogenous new neurons, glia, and endothelial cells, and the proliferation of neurofilaments and vessel-like structures
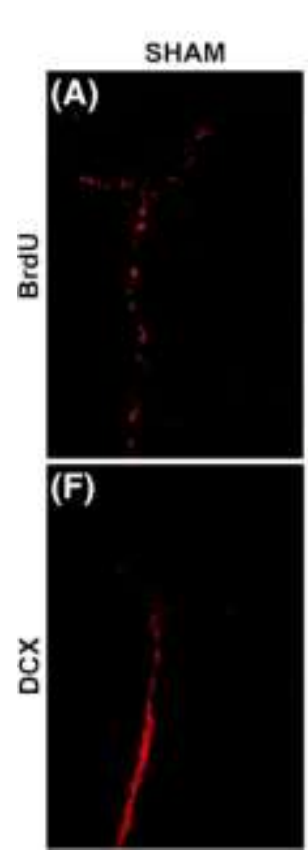
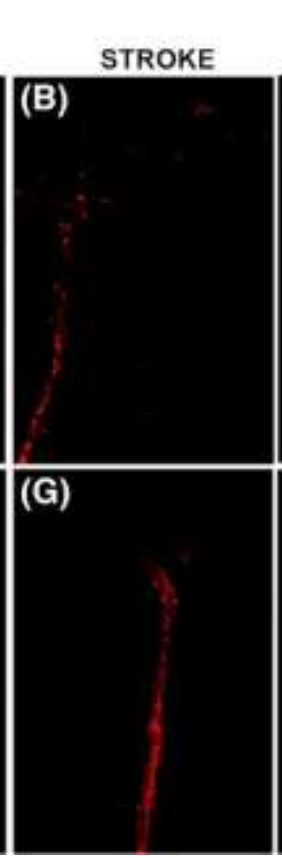

STROKE +
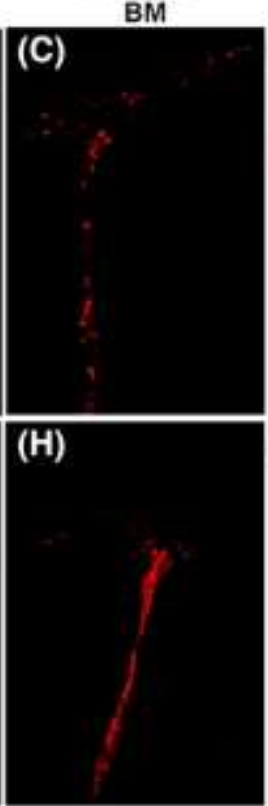

STROKE + $\mathrm{BM}+\mathrm{ASC}$

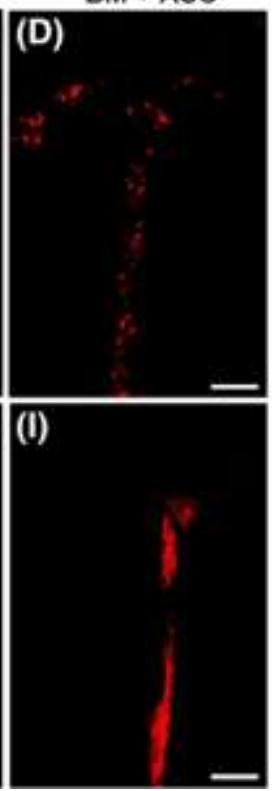

(E)
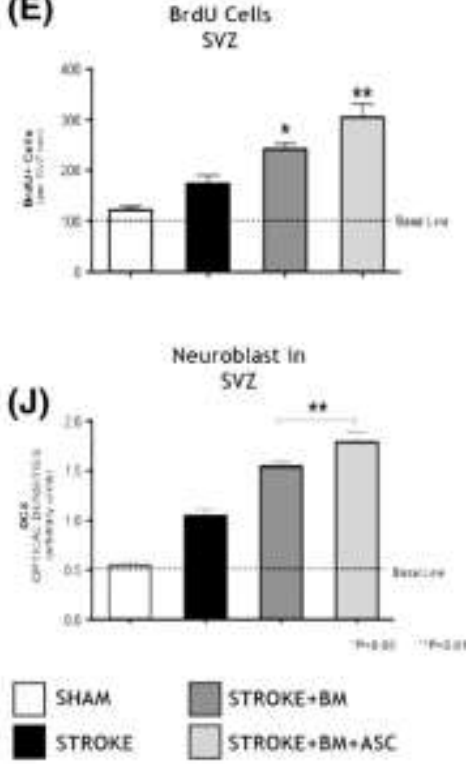

FIGURE 6. Immunohistochemical image showing cell proliferation at the SVZ. A-E: Immunostaining against BrdU. F-J: Immunostaing against doublecortin (DCX) with higher expression of DCX in the SVZ in the experimental group with biomaterials plus ASC. The images correspond the sham group $(A$ and $F)$, stroke (B and $G)$, stroke plus biomaterials $(C$ and $H)$, and stroke plus biomaterials plus adipose stem cells $(D$ and $I)$, and the graph shows the cell count of DCX positive cells. Scale Bar: $200 \mu \mathrm{m}$. 


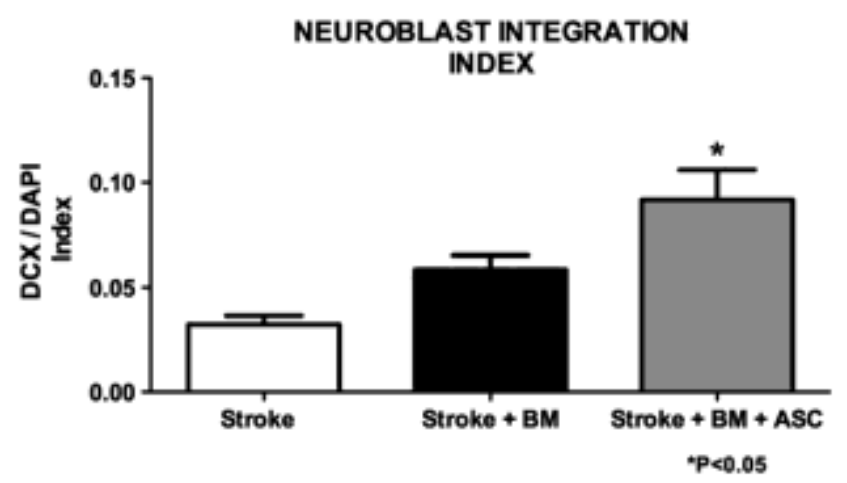

FIGURE 7. Neuroblast integration index. Graph show a data of doblecortin cells express in neuroblast integration index in the vicinity of the lesion. The graph shows a mean $\mathbf{T}$ standard error.

into the biomaterials. Furthermore, the implants increase the proliferation of neuroblasts at the SVZ. The addition of ASCs to the biomaterials increase the proliferative response and the homing effect of biomaterials, plus decreasing the astro- cytic reaction to stroke, implantation surgery and biomate- rials. It also increases the number of neurofilaments found inside the scaffolds and the number of newly formed vessels inside the biomaterials. The biomaterials are easily inte- grated into the core zone, and this integration was even bet- ter when ASC were associated (Supporting Information Figure 2).

ASC has been used to diverse inflammatory pathologies by many authors; being recovery objectives not only in the central nervous system, ${ }^{25,26}$ ASC have shown to increase SVZ

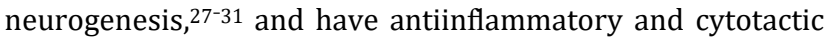
properties when administered in stroke models, ${ }^{32,33}$ and to improve function in animal models, both when administered locally or even through the systemic route. $21,23,34,35$ In addition, it has been shown their neuroprotector effect that intervenes directly in the apoptosis mechanism as describe Wei et al.22,36; and their secretor effect as show Cunningham et al. ${ }^{36}$ However, these approaches do not seem to replace the totally brain tissue lost. 37,38

Conversely, the use of scaffolds leads to true regenera- tion or re-formation of new cerebral tissue, not only reduc- ing the bulk cavitation provoked by stroke, but with the presence of new neurons, neurites and supporting cells and vessels, which might functionally integrate with the sur- rounding brain, as shown Fuhrmann et al., who propose the strategy of favoring the microenviroment.9,39-41

Scaffolds made of HA showed compatibility with the brain, as previously noted. ${ }^{13,14}$ This confirms the innocuous nature of this biomaterial, which can be designed to fit the particularities of the host tissue, therefore favoring the migration of healthy cells adjoining the lesion zone in several models of injury. ${ }^{10,42,43}$ Recently, biomaterials is a growing sector, with very different compositions, such as plasma, PCL, or hydrogels with adhered molecules. All of them share a structural function to restructure the damage tissue.44-48

The combination of HA BM+ASC has a synergistic effect, promotes the proliferative activity in the SVZ (increase BrdU and DCX positive cells), enhancing the attraction of endogenous cells, therefore, promoting an appropriate niche to recovery. ${ }^{4-51}$ The increase in proliferation of the SVZ analyzed by BrdU agrees with the increase of DCX cells in the group with HA plus ASC. In the group where ASC was not administered, a lower amount of DCX and a greater amount of GFAP is observed. So the administration of ASC and its immunomodulatory or anti-inflammatory effects pos- sibly influence the proliferation and differentiation of GFAP and DCX cells. ${ }^{23,49-51}$

Furthermore, ASC increases the biocompatibility and homing ability of HA scaffolds. ${ }^{52-54}$ This is done probably by the antiinflammatory and cytotactic properties of ASC, but not by becoming part of the final implanted struc- ture, since no antigens marking human nuclei were found 30 days after implantation. Also, ASC showed a good inte- gration with HA when the scaffolds were preloaded with these cells, as shown earlier. The combination of the two is safe, as no abnormal cell proliferation of ASC was seen neither in culture nor after implantation. Simultaneously to enhance an appropriate niche and the damage tissue is reduced; the plasticity mechanism is favored. $55^{-57}$

We used immunocompromised animals to explore safety in terms of possible neoplastic proliferation of ASC after implantation. ${ }^{23,48}$ However, these cells have not shown rejection issues when used in immunocompetent rodent stroke models. ${ }^{36,37,58}$

In control animals receiving stroke, newly formed neurons (DCX) coming from the ipsilateral SVZ were seen in the vicinity of the core zone, but were not seen inside the infarcted areas. This confirms the observations by others showing that stroke induces per se a repair reaction, but these cells are unable to stay and organize within the core zone. 5,59

The stroke model we used induced an infarction pattern which is more constant than other models. ${ }^{60}$ However, as this model produces few neurological side effects in the ani- mals, we could not observe if this treatment strategy may produce functional improvement. ${ }^{61^{-6}}$ Further studies in dif- ferent models should be done in rodents, or higher mammals should be tested to determine this.

In conclusion, in stroke, the use of HA and ASC is novel. The present results show how scaffolds of HA implanted at the core zone of a stroke lesion permit the proliferation and migration of new neurons, neurites, glia, and vessels, and the addition of ASC increases this proliferation and homing effect (Supporting Information Figure 2). This may permit formation of new brain tissue after stroke.

\section{ACKNOWLEDGMENTS}

We thank for their skillful assistance at of the Universidad Complutense de Madrid center: ICTS-Centro Nacional de Microscopía Electrónica for technical assistance in SEM; Microscopy and Flow Cytometry Center for confocal sup- port; NMR unit of the Bioimaging Center for technical assistance in MRI support. The authors thank Carolina Fuentes Suárez of U.P.R. for critical reading of the manuscript. 


\section{CONFLICT OF INTEREST}

The authors declare no other conflict of interest.

\section{REFERENCES}

1. Azad TD, Veeravagu A, Steinberg GK. Neurorestoration after stroke. Neurosurg Focus 2016;40:E2.

2. Macrez R, Ali C, Toutirais O, Le Mauff B, Defer G, Dirnagl U, Vivien D. Stroke and the immune system: From pathophysiology to new therapeutic strategies. Lancet Neurol 2011;10:471-480.

3. Faralli A, Bigoni M, Mauro A, Rossi F, Carulli D. Noninvasive strategies to promote functional recovery after stroke. Neural Plast 2013; 2013:854597.

4. Yamashita T, Ninomiya M, Hernández Acosta $P$, García-Verdugo JM, Sunabori T, Sakaguchi M, Adachi K, Kojima T, Hirota Y, Kawase T, Araki N, Abe K, Okano H, Sawamoto K. Subventricular zone-derived neuroblasts migrate and differentiate into mature neurons in the poststroke adult striatum. J Neurosci 2006;26:6627-6636.

5. Arvidsson A, Collin T, Kirik D, Kokaia Z, Lindvall O. Neuronal replacement from endogenous precursors in the adult brain after stroke. Nat Med 2002;8:963-970.

6. Doeppner TR, Hermann DM. Stem cells and progenitor cells in ischemic stroke-fashion or future? Front Cell Neurosci 2015;9:334

7. Zhang ZG, Chopp M. Promoting brain remodeling to aid in stroke recovery. Trends Mol Med 2015;21:543-548.

8. Crapo PM, Medberry CJ, Reing JE, Tottey S, van der Merwe Y, Jones $\mathrm{KE}$, Badylak SF. Biologic scaffolds composed of central ner- vous system extracellular matrix. Biomaterials 2012;33:3539-3547.

9. Ju R, Wen $Y$, Gou R, Wang $Y, X u Q$. The experimental therapy on brain ischemia by improvement of local angiogenesis with tissue engineering in the mouse. Cell Transplant 2014;23(Suppl 1): S83S95.

10. Zhou K, Motamed S, Thouas GA, Bernard CC, Li D, Parkington HC, Coleman HA, Finkelstein DI, Forsythe JS. Graphene functionalized scaffolds reduce the inflammatory response and supports endogenous neuroblast migration when implanted in the adult brain. PLoS One 2016;11:e0151589.

11. Elias PZ, Spector M. Implantation of a collagen scaffold seeded with adult rat hippocampal progenitors in a rat model of penetrating brain injury. J Neurosci Methods 2012;209:199-211.

12. Tang JD, Lampe KJ. From de novo peptides to native proteins: Advancements in biomaterial scaffolds for acute ischemic stroke repair. Biomed Mater 2018;13:034103.

13. Nih LR, Carmichael ST, Segura T. Hydrogels for brain repair after stroke: An emerging treatment option. Curr Opin Biotechnol 2016; 40:155-163.

14. Moshayedi P, Nih LR, Llorente IL, Berg AR, Cinkornpumin J, Lowry WE, Segura T, Carmichael ST. Systematic optimization of an engineered hydrogel allows for selective control of human neural stem cell survival and differentiation after transplantation in the stroke brain. Biomaterials 2016;105:145-155.

15. Lindvall O, Kokaia Z. Stem cell research in stroke: How far from the clinic? Stroke 2011;42:2369-2375.

16. Dong J, Liu B, Song L, Lu L, Xu H, Gu Y. Neural stem cells in the ischemic and injured brain: Endogenous and transplanted. Cell Tissue Bank 2012;13:623-629.

17. Zhang Z, Chopp M. Neural stem cells and ischemic brain. J Stroke 2016;18:267-272.

18. Reis $\mathrm{C}$, Wilkinson M, Reis $\mathrm{H}$, Akyol O, Gospodarev V, Araujo C, Chen $\mathrm{S}$, Zhang JH. A look into stem cell therapy: Exploring the options for treatment of ischemic stroke. Stem Cells Int 2017;2017: 3267352.

19. Jin K, Mao X, Xie L, Greenberg RB, Peng B, et al. Delayed transplantation of human neural precursor cells improves outcome from focal cerebral ischemia in aged rats. Aging Cell 2010;9:1076-1086.

20. Weinstein-Oppenheimer CR, Brown DI, Coloma R, Morales P, Reyna-Jeldes M, Díaz MJ, Sánchez E, Acevedo CA. Design of a hybrid biomaterial for tissue engineering: Biopolymer-scaffold integrated with an autologous hydrogel carrying mesenchymal stemcells. Mater Sci Eng C Mater Biol Appl 2017;79:821-830.

21. Ikegame Y, Yamashita K, Hayashi S, Mizuno H, Tawada M, You F, Yamada K, Tanaka Y, Egashira Y, Nakashima S, Yoshimura S, Iwama T. Comparison of mesenchymal stem cells from adipose tissue and bone marrow for ischemicstroke therapy. Cytotherapy 2011;13:675-685.

22. Wei $X$, Zhao L, Zhong J, Gu H, Feng D, Johnstone BH, March $\mathrm{KL}$, Farlow MR, Du Y. Adipose stromal cells-secreted neuroprotective media against neuronal apoptosis. Neurosci Lett 2009;462:76-79.

23. Gómez-Pinedo $U$, Sanchez-Rojas L, Benito-Martin MS, Lendinez C, León-Espinosa G, Rascón-Ramirez FJ, Herrero J, Castro B, Moreno-Jiménez L, Del Olmo M, Matias-Guiu JA, Matias-Guiu J, Barcia JA. Evaluation of the safety and efficacy of the therapeutic potential of adipose-derived stem cells injected in the cerebral ischemic penumbra. J Stroke Cerebro- vasc Dis 2018;27:24532465.

24. Rodríguez-Pérez E, LloretCompañ A, MonleónPradas M, MartínezRamos C. Scaffolds of hyaluronic acid-poly(ethyl acrylate) interpenetrating networks: characterization and in vitro studies. Macromol Biosci 2016;16:1147-1157.

25. Davoust C, Plas B, Béduer A, Demain B, Salabert AS, Sol JC, Vieu C, Vaysse L, Loubinoux I. Regenerative potential of primary adult human neural stem cells on micropatterned bio-implants boosts motor recovery. Stem Cell Res Ther 2017;8:253-266.

26. Bateman ME, Strong AL, Gimble JM, Bunnell BA. Using fat to fight disease: A systematic review of non-homologous adipose-derived stromal/stem cell therapies. Stem Cells 2018;36:1311-1328.

27. Seo JH, Kim H, Park ES, Lee JE, Kim DW, Kim HO, Im SH, Yu JH, Kim JY, Lee MY, Kim CH, Cho SR. Environmental enrichment synergistically improves functional recovery by transplanted adipose stem cells in chronic hypoxic-ischemic brain injury. Cell Transplant 2013;22:1553-1568.

28. Palma-Tortosa S, García-Culebras A, Moraga A, Hurtado O, PerezRuiz A, Durán-Laforet V, Parra J, Cuartero MI, Pradillo JM, Moro MA, Lizasoain I. Specific features of SVZ neurogenesis after cortical ischemia: A longitudinal study. Sci Rep 2017;7:16343.

29. Lu J, Manaenko A, Hu Q. Targeting adult neurogenesis for Poststroke therapy. Stem Cells Int 2017;2017:5868632.

30. Faiz M, Sachewsky N, Gascón S, Bang KW, Morshead CM, Nagy A Adult neural stem cells from the subventricular zone give rise to reactive astrocytes in the cortex after stroke. Cell Stem Cell2015;17: 624-634.

31. Moraga A, Pradillo JM, García-Culebras A, Palma-Tortosa S, Ballesteros I, Hernández-Jiménez M, Moro MA, Lizasoain I. Aging increases microglial proliferation, delays cell migration, and decreases cortical neurogenesis after focal cerebral ischemia. $J$ Neuroinflammation 2015;12:87.

32. Oh JS, Park IS, Kim KN, Yoon DH, Kim SH, et al. Transplantation of an adipose stem cell cluster in a spinal cord injury. Neuroreport 2012;23:277-282.

33. Erba P, Terenghi G, Kingham PJ. Neural differentiation and therapeutic potential of adipose tissue derived stem cells. Curr Stem Cell Res Ther 2010;5(2):153-160.

34. Grudzenski S, Baier S, Ebert A, Pullens P, Lemke A, Bieback K, Dijkhuizen RM, Schad LR, Alonso A, Hennerici MG, Fatar M. The effect of adipose tissue-derived stem cells in a middle cerebral artery occlusion stroke model depends on their engraftment rate. Stem Cell Res Ther 2017;8:96

35. Egashira $Y$, Sugitani S, Suzuki $Y$, Mishiro K, Tsuruma K, Shimazawa $\mathrm{M}$, Yoshimura S, Iwama T, Hara $\mathrm{H}$. The conditioned medium of murine and human adipose-derived stem cells exerts neuroprotective effects against experimental stroke model. Brain Res 2012;1461:8795.

36. Cunningham CJ, Redondo-Castro E, Allan SM. The therapeutic potential of the mesenchymal stem cell secretome in ischaemic stroke. J Cereb Blood Flow Metab 2018;38:1276-1292.

37. Gutiérrez-Fernández $M$, Otero-Ortega L, Ramos-Cejudo J, Rodríguez-Frutos B, Fuentes B, Díez-Tejedor E. Adipose tissuederived mesenchymal stem cells as a strategy to improve recovery after stroke. Expert Opin Biol Ther 2015;15:873-881.

38. Mastro-Martínez I, Pérez-Suárez E, Melen G, González-Murillo Á, Casco F, Lozano-Carbonero N, Gutiérrez-Fernández M, DíezTejedor E, Casado-Flores J, Ramírez-Orellana M, SerranoGonzález A. Effects of local administration of allogenic adipose tissue-derived mesenchymal stem cells on functional recovery in experimental traumatic brain injury. Brain Inj 2015;29: 1497-1510. 
39. Martınez-Ramos C, Valles-Lluch A, Verdugo JM, Ribelles JL, Barcia Albacar JA, Orts AB, Soria López JM, Pradas MM. Channeled scaffolds implanted in adult rat brain. J Biomed Mater Res A 2012; 100A:3276-3286.

40. Pérez-Garnes M, Barcia JA, Gómez-Pinedo U, Monleón Pradas M, Vallés-Lluch A (November 26th 2014). Materials for Central Nervous System Tissue Engineering, Cells and Biomaterials in Regenerative Medicine Daniel Eberli, IntechOpen, DOI: 10.5772/59339

41. Führmann T, Anandakumaran PN, Shoichet MS. Combinatorial therapies after spinal cord injury: How can biomaterials help? Adv Healthc Mater 2017;6(10):1601130.

42. Wang Y, Wei YT, Zu ZH, Ju RK, Guo MY, Wang XM, Xu QY, Cui FZ. Combination of hyaluronic acid hydrogel scaffold and PLGA microspheres for supporting survival of neural stem cells. Pharm Res 2011;28:1406-1414.

43. Nih LR, Moshayedi P, Llorente IL, Berg AR, Cinkornpumin J, Lowry WE, Segura T, Carmichael ST. Engineered HA hydrogel for stem cell transplantation in the brain: Biocompatibility data using a design of experiment approach. Data Brief 2016;10:202-209.

44. Gómez-Pinedo U, Sanchez-Rojas L, Vidueira S, Sancho FJ, MartínezRamos C. Bridges of biomaterials promote nigrostriatal pathway regeneration. J Biomed Mater Res Part B 2018;00B:000-000.

45. Arnal-Pastor M, Martınez-Ramos C, Valles-Lluch A, Monleon Pradas $M$. Influence of scaffold morphology on co-cultures of human endothelial and adipose tissue-derived stem cells. J Biomed Mater A 2016;104:1523-1533.

46. Gao S, Zhao P, Lin C, Sun Y, Wang Y, Zhou Z, Yang D, Wang X, Xu $\mathrm{H}$, Zhou F, Cao L, Zhou W, Ning K, Chen X, Xu J. Differentiation of human adipose-derived stem cells into neuron-like cells which are compatible with photocurable three-dimensional scaffolds. Tis- sue Eng Part A 2014;20:1271-1284.

47. Yuan X, Wei Y, Villasante A, Ng JJD, Arkonac DE, Chao PG, VunjakNovakovic G. Stem cell delivery in tissue-specific hydrogel enabled meniscal repair in an orthotopic rat model. Biomaterials 2017;132: 59-71.

48. Nih LR, Gojgini S, Carmichael ST, Segura T. Dual-function injectable angiogenic biomaterial for the repair of brain tissue following stroke. Nat Mater 2018;17(7):642-651.

49. Lin R, Lacovitti L. Classic and novel stem cell niches in brain homeostasis and repair. Brain Res 2015;1628:327-342.

50. Zhang RL, Chopp M, Roberts C, Liu X, Wei M, Nejad-Davarani SP, Wang $X$, Zhang ZG. Stroke increases neural stem cells and angiogenesis in the neurogenic niche of the adult mouse. PLoS One 2014;9:e113972.

51. Ruddy RM, Morshead CM. Home sweet home: The neural stem cell niche throughout development and after injury. Cell Tissue Res 2018 Jan;371:125-141.
52. Mora-Lee S, Sirerol-Piquer MS, Gutiérrez-Pérez M, Gomez- Pinedo U, Roobrouck VD, López T, Casado-Nieto M, Abizanda G, Rabena MT, Verfaille C, Prósper F, García-Verdugo JM. Therapeutic effects of hMAPC and hMSC transplantation after stroke in mice. PLoS One 2012;7(8):e43683.

53. Boisserand LS, Kodama T, Papassin J, Auzely R, Moisan A, Rome C, Detante O. Biomaterial applications in cell-based therapy in experimental stroke. Stem Cells Int 2016;2016:6810562.

54. Adams AM, Arruda EM, Larkin LM. Use of adipose-derived stem cells to fabricate scaffoldless tissue-engineered neural conduits in vitro. Neuroscience 2012;201:349-356.

55. Ottoboni L, Merlini A, Martino G. Neural stem cell plasticity: Advantages in therapy for the injured central nervous system. Front Cell Dev Biol 2017;5:52.

56. Sandvig I, Augestad IL, Håberg AK, Sandvig A. Neuroplasticity in stroke recovery. The role of microglia in engaging and modifying synapses and networks. Eur J Neurosci 2018;47(12):1414-1428.

57. Le Friec A, Salabert AS, Davoust C, Demain B, Vieu C, Vaysse L, Payoux $P$, Loubinoux I. Enhancing plasticity of the central nervous system: drugs, stem cell therapy, and neuro-implants. Neural Plast 2017;2017:2545736.

58. Traystman RJ. Animal models of focal and global cerebral ische- mia. ILAR J 2003;44:85-95.

59. Doeppner TR, Kaltwasser B, Teli MK, Sanchez-Mendoza EH, Kilic E, Bähr M, Hermann DM. Post-stroke transplantation of adult subventricular zone derived neural progenitor cells: A comprehensive analysis of cell delivery routes and their underlying mechanisms. Exp Neurol 2015;273:45-56.

60. Karatas H, Erdener SE, Gursoy-Ozdemir Y, Gurer G, Soylemezoglu F, Dunn AK, Dalkara T. Thrombotic distal middle cerebral artery occlusion produced by topical $\mathrm{FeCl}(3)$ application: A novel model suitable for intravital microscopy and thrombolysis studies. J Cereb Blood Flow Metab 2011;31:1452-1460.

61. Karatas H, Eun Jung J, Lo EH, van Leyen K. Inhibiting 12/- 15lipoxygenase to treat acute stroke in permanent and tPA induced thrombolysis models. Brain Res 2018;1678:123-128.

62. Zhou F, Gao S, Wang L, Sun C, Chen L, Yuan P, Zhao H, Yi Y, Qin Y, Dong Z, Cao L, Ren H, Zhu L, Li Q, Lu B, Liang A, Xu GT, Zhu H, Gao Z, Ma J, Xu J, Chen X. Human adipose-derived stem cells partially rescue the stroke syndromes by promoting spatial learning and memory in mouse middle cerebral artery occlusion model. Stem Cell Res Ther 2015;6:92.

63. Mora-Lee S, Sirerol-Piquer MS, Gutiérrez-Pérez M, López T, CasadoNieto M, Jauquicoam C, Abizanda G, Romaguera-Ros M, GomezPinedo U, Prósper F, García-Verdugo JM. Histological and ultrastructural comparison of cauterization and thrombosis stroke models in immune-deficient mice. J Inflamm 2011;8(1):28. 